\title{
Aprendizagem da leitura: preditores emergentes na pré-escola
}

\section{Learning of reading: emerging predictors in pre-school}

Márcia Regina Melchior Landim*

Universidade de Santa Cruz do Sul

Santa Cruz do Sul, Rio Grande do Sul, Brasil

Onici Claro Flôres**

Universidade de Santa Cruz do Sul

Santa Cruz do Sul, Rio Grande do Sul, Brasil

\begin{abstract}
Resumo: A criança começa a desenvolver habilidades leitoras e de escrita antes do processo de alfabetização promovido pela escola. Compreender essa aprendizagem precedente e a sua evolução possibilita, entre outras coisas, identificar - na pré-escola - que habilidades são capazes de predizer o desempenho futuro. Dessa forma, através do presente ensaio propõe-se apontar algumas estratégias que pais e professores de Pré-Escola podem utilizar a fim de favorecer a aprendizagem inicial da leitura, prestando-se tais estratégias a servir de andaimes para o desempenho proficiente em leitura e escrita posterior. Para tanto se faz uma revisão da literatura pertinente ao tema, sobretudo, em neurociências e a ela se reúne a experiência docente da pesquisadora proponente do tema focalizado.
\end{abstract}

Palavras-chave: Leitura. Aprendizagem. Ensino. Preditores de leitura.

Abstract: The child begins to develop reading and writing skills prior to the school-sponsored literacy process. Understanding this prior learning and its evolution makes it possible, among other things, to identify - in preschool - which skills are able to predict future performance. In this way, the present essay proposes to point out some strategies that parents and preschool teachers can use in order to favor the initial learning of reading, providing such strategies to serve as scaffolding for proficient performance in reading and later writing. To do so, a review of the relevant literature on the subject, especially in neurosciences, is carried out and the teaching experience of the researcher proposing the focused theme is gathered.

Keywords: Reading. Learning. Teaching. Reading predictors.

\section{INTRODUÇÃO}

É consenso entre os pesquisadores das neurociências (DEHAENE, 2012; SCLIAR-CABRAL, 2013 e 2015; MORAIS, 2013 e 2014) que o aprendizado da leitura não acontece de forma instantânea, tampouco que seja simples. Caso fosse diferente, não existiria um número tão grande de analfabetos no país apesar de as crianças terem de frequentar a escola até os 14 anos ou, então, teria diminuído o número de crianças frequentando a escola e mesmo assim, depois de um, dois, três ou até mais anos de escolarização ainda não dominando a leitura. Os pesquisadores da área da leitura têm-se concentrado nesse problema e suas pesquisas demonstram que ler envolve complexa

\footnotetext{
* Doutoranda do Programa de Pós-Graduação em Letras, Universidade de Santa Cruz do Sul - UNISC, Santa Cruz do Sul, RS, Brasil. E-mail: soramarcia@gmail.com.

${ }^{* *}$ Professora do Programa de Pós-Graduação em Letras, Universidade de Santa Cruz do Sul - UNISC, Santa Cruz do Sul, RS, Brasil. E-mail: oflores@unisc.br.
} 
atividade cerebral paralela, simultânea e plena de informações linguísticas ortográficas e fonologicamente encapsuladas em um código (ARAÚJO, 2011). Nesse sentido, saber ler é desenvolver a capacidade de decifrar esse código, atribuindo um sentido preciso a cada uma das palavras escritas que compõe a frase; além disso, o leitor iniciante também precisa "criar um mecanismo capaz de reconhecer todas as palavras escritas" (ISCOA, 2011, p.52). Assim, a chave para se tornar um leitor eficiente, de acordo com Ischoa (2011), está no reconhecimento das palavras, o qual ocorre de forma automática e inconsciente.

Além de Iscoa, Snowling e Hulme (2013, p.19) afirmam ser o reconhecimento de palavras fundamental para a leitura, pois todos os demais processos leitores dependem dele. Ou seja, quando os processos de reconhecimento não funcionam de forma eficiente, a leitura torna-se lenta, sem compreensão. Os autores citados ainda justificam a importância do reconhecimento das palavras ao dizer que reconhecer as palavras envolve ter acesso às informações que estão armazenadas na memória e esse reconhecimento (auditivo e visual) envolve um processo de recuperação de informações sobre a forma falada e o reconhecimento do seu significado através da leitura da palavra escrita. Partindo dessa informação, a de que o reconhecimento de palavras é a base da leitura, tem-se de pensar sobre como possibilitar à criança em processo de alfabetização, o acesso a esse reconhecimento. A questão relaciona-se a investigar que memórias podem ser formadas, para que o reconhecimento da palavra através da leitura feita pelo professor, aliada à visão da palavra escrita, atue como um gatilho para a recuperação das informações sobre a forma falada, já existente na memória do leitor iniciante.

\section{MECANISMOS COGNITIVOS QUE PROPICIAM O APRENDIZADO DA LEITURA}

Dessa forma, relacionam-se a seguir os mecanismos cognitivos envolvidos nas diferentes fases do desenvolvimento da inter-relação leitura-escrita, desde o primeiro contato da criança com as letras até ao momento em que essa criança se torna um leitor competente, apto a ler com prosódia adequada e fluência. Conforme disseram Reis, Faísca, Castro e Petersson (2010), ao longo dessa aprendizagem acontece "uma alteração dinâmica dos processos cognitivos subjacentes à leitura", em que a criança passa de uma leitura alicerçada em processos sublexicais para uma leitura que recorre ao reconhecimento ortográfico das palavras. Por isso, compreender o desenvolvimento e as fases que antecedem esse aprendizado pode resultar em um ensino consistente com resultados exitosos em leitura.

Preocupada com questões atinentes à alfabetização, Scliar-Cabral (2015) enfatiza a necessidade de a criança ser ajudada a descobrir os princípios do sistema alfabético. $\mathrm{O}$ professor alfabetizador, diz a autora, precisa estar consciente de que não é porque a criança é falante de uma língua, cujo sistema de escrita é alfabético, que ela terá naturalmente conhecimento de como se processa a leitura. De fato, a leitura é uma habilidade que se aprende, logo, a criança não nasce com ela. Para a autora, a criança/leitor principiante precisa aprender a analisar desde os traços que constituem as letras, a direção desses traços (vertical-horizontal) e a diferença entre esquerda e direita. Esses aspectos 
costumam passar despercebidos para um leitor proficiente, visto que o processamento da leitura é automático para ele, mas tais peculiaridades fazem toda a diferença para o iniciante. Para exemplificar, a autora (SCLIAR-CABRAL, 2015) destaca as letras (grafemas) "p", "b”, "q" e “d”, que são constituídas pelos mesmos traços, porém em direções diferentes. $\mathrm{Na}$ leitura das palavras, porém, esses traços aparentemente insignificantes determinam valores sonoros diferentes, a depender da forma de seu traçado no papel, ou digitado na tela do computador; daí a sua importância decisiva.

É importante destacar que esses aspectos topográficos mínimos tão relevantes para a escrita precisam ser ensinados. Sobre o tema Dehaene (2012) detalha a questão da invariancia perceptiva - capacidade que os neurônios têm de reconhecer as invariâncias das letras, como os traços gráficos que as distinguem, e abstrair o que é variante, como estilo, forma e tamanho -, que é o que permite identificar todas as palavras, sejam elas escritas em letra de imprensa ou manuscrita, maiúscula ou minúscula e em qualquer fonte. Segundo o autor, apenas as pequenas diferenças (os traços) que distinguem uma letra da outra e que são representativas de cada uma delas, e constituem o seu processo de normalização.

Esse processo pode ser facilitado pelo professor desde a educação infantil, ao propor atividades que levem a criança a perceber a diferença entre traços: linhas, curvas e retas e a direção desses traços, como, por exemplo, riscar as letras com o dedo na areia, desenhar no ar os traços para a criança descobrir a letra, reproduzir o traçado das letras com massa de modelar, ou, com os olhos vendados, descobrir as letras apenas pelo tato, entre outras atividades lúdicas, que podem tornar significativa a aprendizagem do nome e o traçado das letras. Além disso, ao fazer a leitura de uma história, o(a) professor(a) pode mostrar que ele(ela) começa a leitura de cima para baixo, no topo da página e vai até o final, que lê da esquerda para a direita, que o texto é constituído de palavras, que existem espaços em branco entre as palavras que constituem a história, além de analisar elementos pré-textuais, como também orientar as crianças a observar bem a capa do livro, as ilustrações, descobrir quem é o(a) autor(a) da história, com a intenção de familiarizá-las com o texto impresso, mostrando as nuanças da língua escrita. Quanto mais cedo a criança se aproximar da escrita como objeto cultural manipulável, interagindo naturalmente com ela através de atividades de leitura e escrita, mais facilidade terá para ler e escrever com desenvoltura (SENECHAL, LeFEVRE, THOMAS, \& DALEY, 1998).

Outro desafio para uma criança aprender a ler é ter ciência da diferença entre fala e leitura. De acordo com Scliar-Cabral (2012), a fala é um contínuo, ou seja, enquanto fala a criança não tem de se preocupar em separar as palavras, as sílabas ou os fonemas; em suma, para falar ela não precisa identificar os contrastes entre os segmentos que constituem a sílaba e muito menos desmembrar a sílaba formada em unidades menores os fonemas. Nesse ponto evidencia-se outra vez a necessidade de se desenvolver um ensino planejado, que leve a criança a "analisar conscientemente a fala, desmembrando a cadeia em palavras, essas em sílabas e, o que é mais difícil, separar as consoantes das vogais" (SCLIAR-CABRAL, 2013, p.14). A esta aprendizagem, a autora dá o nome de tomada de consciência fonológica. 
A consciência fonológica pode ser definida como a "capacidade de identificar e discriminar sons linguísticos distintivos" (OLIVEIRA, 2007, p. 95). Ela é, além disso, um dos preditores de leitura que mais tem interessado aos pesquisadores nos últimos anos, principalmente no que se refere a sua importância para a alfabetização (CAPOVILLA \& CAPOVILLA, 2003; CARDOSO-MARTINS, 1995; GUIMARÃES, 2005 e MALUF, 2010). Para Peter Bryant y Usha Goswami (1987, p.439), a "descoberta da existência de uma relação forte entre a consciência fonológica da criança e seus progressos na aprendizagem da leitura é um dos maiores êxitos da psicologia contemporânea".

Fazendo a intersecção entre desenvolvimento da consciência fonológica e identificação de palavras, faz-se presente um dos componentes básicos da leitura inicial: a decodificação - o outro é a compreensão - (NAVAS et al, 2009). Para Siqueira (2006, p.33), a decodificação é a "etapa mais básica da aprendizagem da leitura". Nessa etapa, o leitor associa um sinal gráfico a um nome ou a um som da língua, isto é, acontece a conversão grafema-fonema, e, nela, o leitor não alcança ainda o reconhecimento da palavra; por se tratar de uma atividade cognitiva lenta e de muito esforço, o leitor consegue ler a sílaba ao fazer a junção dos fonemas, mas dificilmente, na reunião das sílabas, consegue ler/reconhecer a palavra como um todo. Resta evidente, que para fazer o reconhecimento do traço de tinta sobre o papel ou na tela, o leitor precisa já ter tido alguma experiência com a escrita e a leitura, precisa já ter entendido que aquele traço não é um desenho, que ele representa uma letra, que por sua vez tem um nome e é representada na fala por um som (fonema). Em decorrência, a criança só vai decodificar quando chegar nesta fase/estágio do seu aprendizado. E só vai identificar palavras quando conseguir fazer a relação entre o grafema e o fonema. "A decodificação é o único mecanismo gerador de identificação de palavras, ou seja, o único que permite identificar todas as palavras escritas que formam parte do vocabulário do leitor.” (ISCOA, 2011, p.55).

\section{ENTÃO, SE PARA RECONHECER PALAVRAS, O LEITOR PRECISA SABER DECODIFICAR, COMO ENSINAR À CRIANÇA A DECODIFICAR?}

Para responder à pergunta proposta no subtítulo, faz-se a comparação entre o processo de alfabetização e o desenvolvimento da língua oral já efetivada pela criança. A aquisição da fala é natural. Assim, conforme vai sendo exposta a situações comunicativas e interagindo com seus pares, a criança começa a perceber como os adultos se comunicam e aos poucos vai se apropriando da linguagem oral e se comunicando, sendo capaz de compreender o sentido das palavras que ouve, assimilando-as e utilizando-as em suas conversas. Mais tarde, com a maturação cognitiva, que vai variar de criança para criança, e que ainda depende do contexto familiar, cultural, socioeconômico, entre outras variáveis, avança nesse conhecimento e começa a perceber particularidades da língua, como as rimas, por exemplo. Normalmente, nesta etapa, começa a surgir o interesse pelo nome letras. E é nessa etapa do desenvolvimento que a criança precisa ser orientada, pois a consciência dos fonemas e o reconhecimento das letras não costumam acontecer naturalmente, precisam ser ensinados. 
Oliveira (2007) lista algumas competências específicas que possibilitam à criança aprender a ler. Essas competências estão reunidas, de acordo com o autor, em três grupos. O primeiro grupe reúne as competências que servem de fundamento para a aprendizagem da leitura. São elas: a familiaridade com livros, a consciência fonológica e a metalinguagem; no segundo grupo estão os pré-requisitos: a consciência fonêmica e o princípio alfabético e, no último grupo, os requisitos referem-se à decodificação e à fluência. Como se vê, os fundamentos estão muito relacionados à língua oral e, fundamentalmente, à importância de a criança viver em um ambiente letrado, rico de experiências em que pais, avós, irmãos, familiares leiam, contem histórias, interajam com ela, façam brincadeiras, conversem, cantem cantigas de roda, de ninar, numa relação compartilhada com o mundo cultural. Isso é altamente benéfico. Para Morais, a vontade de aprender a ler surgirá dessa relação da criança com o material escrito, tendo os pais (ou cuidadores) como espelho. A leitura partilhada é citada pelo autor como "um instrumento de grande utilidade para preparar a aprendizagem da leitura" (MORAIS, 2013, p.2). Morais ainda enumera outras vantagens dessa prática para o aprendizado da criança, dentre as quais destaca a aquisição de vocabulário, a interação com o material escrito, a evocação de conceitos abstratos, a aquisição de conhecimentos que serão importantes para a aprendizagem da leitura, como a direção da leitura, a formação das palavras por uma sequência de letras, os espaços vazios, entre tantas outras.

A leitura partilhada deve tornar-se uma prática constante e generalizada, primeiro na creche e na educação infantil, e, depois, nos primeiros anos de escolaridade, com pequenos livros que as crianças já possam ler com o professor. (MORAIS, 2013, p. 5).

A influência da leitura para o desenvolvimento cognitivo da criança já foi devidamente avaliada por Stanovich (1986). O autor, ao propor uma analogia com o texto bíblico, destaca o que chama de "efeito Matheus". Segundo ele, o sucesso precoce nas habilidades de leitura, geralmente, leva a sucessos posteriores na leitura. Se a criança tiver contato com livros e essa for uma prática prazerosa, ela tenderá a continuar lendo mais e melhor; o contrário também é verdadeiro: se lê pouco e com dificuldade, tenderá a desinteressar-se e abandonar a leitura e até a escola. Esse fato, relatado através de pesquisa, reforça o papel da leitura partilhada, mencionada anteriormente: se os pais têm o hábito de ler para os filhos, neles despertarão o desejo de ler; se a criança não tiver esse estímulo, dificilmente se interessará por livros. O ambiente familiar (cultural e social) rico e diversificado é também um fator decisivo para o processo de aprendizagem da leitura. Ainda sobre as consequências do "efeito Matheus", pode-se inferir que o insucesso em leitura nos primeiros anos de escolarização tende a associar-se com frustração e desestímulo, pois à medida que a criança fica para trás em leitura, aumenta a diferença entre ela e os colegas e isso compromete o seu desempenho escolar, criando dificuldade em outras áreas do conhecimento que exigem leitura e compreensão.

Voltando às competências citadas por Oliveira (2007), as primeiras acontecem de maneira mais informal, já as demais requerem ensino formal, planejado. Na pré-escola, por exemplo, os professores podem propor-se a desenvolver a consciência fonológica dos alunos através das mais variadas atividades, como identificar diferentes sons, a sua origem, 
quem os produziu, comparar um som com o outro (atividades multissensoriais); depois, através de cantigas e parlendas, identificar as rimas, imitar os sons de animais ou coisas, brincar com as palavras, trocando uma parte delas, fazendo rimas, encontrando palavras escondidas, etc. Essas "brincadeiras" contribuem para que a criança comece a desenvolver a metalinguagem, na medida em que ela terá que pensar e falar sobre a língua, prestar atenção à pronúncia, dar definições. Para atingir ou (re)criar o princípio alfabético de sua língua materna, a criança terá que conhecer o alfabeto e ter desenvolvido a consciência fonêmica, aprendizagem que está relacionada à decodificação. Consciência fonêmica é o entendimento consciente de que cada palavra é constituída por uma série de fonemas (sons distintivos) e é ela que leva a criança a descobrir o princípio alfabético. "Para desenvolver consciência fonêmica é preciso falar de nomes de letras e sons". (OLIVEIRA, 2007, p.98)

Relacionando teoria e prática docente, por vezes, o investigador depara-se com o que acontece em muitas classes de alfabetização, em que o ensino é centrado apenas no nome e na grafia das letras. Nessas aulas, o professor costuma ensinar a criança a juntar "B"+ "A" e tem o "BA", ignorando as relações oralidade-escrita, grafema-fonema. Para Soares (2017), o problema está no objeto da alfabetização, ou seja, o professor não sabe o que ensinar quando ensina a língua escrita: "ensina-se a ler ou ensina-se a escrever?” A autora argumenta isso ao dizer que até 1980, privilegiavam-se os "métodos de leitura", limitando a escrita a cópias ou ao ditado, depois, com o construtivismo a partir de 1980, a escrita passou a desempenhar papel importante, surgindo a escrita "espontânea", a escrita "inventada", privilegiando-se a escrita de textos de diferentes gêneros, não como atividade consciente sobre a natureza da língua, mas como expressão do modo de pensar a escrita pela criança.

O principal é não identificar ler com escrever, pois se a leitura jamais pode ser dissociada da escrita, com ela não pode se confundir, uma vez que ambas são habilidades linguísticas distintas e irredutíveis; de fato, só existe leitura se houver marcas da escrita no papel, mas é importante ponderar a respeito do que se ensina quando se ensina a ler.

Hulme (1981), Hulme e Bradley (1984), Hulme, Monk e Ives (1987) desenvolveram estudos que mostram a importância de escrever as letras para a aquisição das relações entre fonemas e grafemas. Para isso, eles utilizaram diferentes métodos de lidar com as letras: copiar, usar cartões, usar cartelas. Nesses estudos, foi feita a comparação do tempo de aprendizagem das crianças para aprender as relações entre fonemas e grafemas e os resultados foram mais favoráveis ao grupo que escrevia ou copiava as letras. Deduz-se, então, que "a atividade motora promove a memória, força o aluno a prestar a atenção e manter na memória a imagem da palavra de forma mais diferenciada" (ARAÚJO, 2011, p.98). Ao escrever, a criança mobiliza o processamento visual-espacial, na medida em que identifica a letra a ser escrita e visualiza a sua forma, por isso no processo de alfabetização deve-se dar atenção à escrita tanto quanto se dá à leitura e vice-versa, pois existe uma relação de dependência entre ambas as habilidades. Para obter sucesso em uma é preciso que a outra seja entendida de forma consciente. 


\section{LER E ESCREVER SÃO DUAS HABILIDADES LINGUÍSTICAS DISTINTAS, AINDA QUE RELACIONADAS ESTREITAMENTE}

A questão crucial a ser encarada pelo alfabetizador é que ler e escrever são habilidades linguísticas distintas e o aluno além de aprender o nome da letra precisa aprender, também, o modo como é produzida ou emitida a tal letra, ou seja, o som linguístico distintivo com que tem de ser lida.

Além do mais, o desempenho da criança também vai depender da transparência ou consistência do código ortográfico, ou seja, do grau de consistência/estabilidade entre os fonemas e grafemas. Em um estudo desenvolvido por Pinto (1998), a autora enfocou o grau de opacidade/transparência do português e, mais tarde, em outro realizado por Seymour, Aro e Erskine (2003) foram mapeados e descritos a complexidade silábica e o grau de transparência/opacidade das ortografias de diferentes escritas. Em ambas as pesquisas foi constatado que, dependendo da língua, as relações entre a cadeia fonológica e o sistema ortográfico são mais ou menos complexas e ambíguas. O grau de transparência/opacidade diz respeito aos padrões de codificação dos fonemas em grafemas. Nas ortografias transparentes, as correspondências são coerentes e consistentes - cada fonema corresponde a uma letra. Já nas ortografias opacas, as correspondências são variáveis, inconsistentes e arbitrárias - o mesmo grafema pode representar diferentes fonemas; diferentes grafemas podem representar o mesmo fonema, combinações de letras podem representar fonemas.

Soares (2017) cita alguns trabalhos (SPRENGER-CHAROLES, 2004; PAULESU et al, 2001; WIMMER e FRITH, 1997) comprobatórios de que os níveis de profundidade ortográfica em diferentes línguas influenciam aspectos como o tempo de aprendizagem necessário para vencer determinada fase, as estruturas cognitivas que se formam e as unidades linguísticas que são enfatizadas em cada nível. Sucena, Castro e Seymor (2009) aditam, ainda, que o português brasileiro tem uma estrutura silábica simples, mas, na escala da transparência/opacidade, fica em um nível intermediário, sendo caracterizado o sistema de escrita do português como relativamente transparente. Um exemplo disso, no sistema vocálico, as cinco vogais representam 12 fonemas; no sistema consonantal, algumas consoantes, como o "X", por exemplo, pode ter diferentes pronúncias (exame, máximo, mesma etc), o que torna o estabelecimento da correspondência grafema-fonema difícil para quem está em processo de aprendizagem. Essa dificuldade não afeta os leitores proficientes que fazem o reconhecimento visual de forma automática e inconsciente. Mas, para chegar a esse estágio, é preciso antes que alguém tenha ensinado quais são as letras do alfabeto, seus nomes, a produção fonêmica de cada grafema e as formas possíveis de combinar a sequência para ler e escrever. A criança aos poucos conseguirá dominar as irregularidades da ortografia da língua, que no caso do português brasileiro não são muitas, se o ensino começar pelas regularidades, ou seja, pelas palavras de uso mais frequente e regular. A lógica é do mais simples para o mais complexo. Some-se a isso o cultivo da leitura pelos adultos que fazem parte do ambiente familiar e escolar da criança (pais, professores), pois é através da leitura, da escuta de leituras que a criança desenvolve a imaginação e a criatividade, amplia seu vocabulário e reforça a memorização das palavras 
lidas, incluindo-as no léxico mental ortográfico de palavras que contenham ou não irregularidades.

Uma alfabetização de qualidade, entendida como aquela que possibilita às pessoas o domínio do sistema alfabético da escrita e, consequentemente, a desenvoltura em leitura - uma leitura hábil, rápida, fluente e compreensiva -, é o grande desafio que têm hoje os sistemas de ensino, em especial, os professores do Ensino Fundamental. Embora alguns até defendam o uso de determinados manuais ou métodos, o que se deve considerar, sobretudo, são as evidências obtidas em investigações, pois o professor deve ser um bom aprendiz para poder ser um bom professor.

Em suma, a criança estará preparada para a leitura quando possuir os fundamentos ou os pré-requisitos da leitura; alguns deles, como já explicado, poderão se apreendidos nas interações com os adultos com os quais a criança convive, seja ouvindo a leitura de histórias, seja através de brincadeiras, outros deverão ser ensinados formalmente na escola, a partir da educação infantil. E se, ao chegar à classe de alfabetização, a criança ainda não os possuir os requisitos necessários, a escola precisará supri-los, elaborando um programa que contemple as competências referidas ao longo deste texto, pois sem recepção não há produção, ou seja, primeiro se recebe o input para que depois se produza o output. Primeiro, o professor/pais precisam fornecer os insumos necessários à criança, lendo, contando histórias, deixando-as manipular livros, para só então esperar que ela leia e escreva. O que se sabe é que enquanto a criança não tiver consciência do funcionamento da língua escrita, esta é um mero desenho.

Alcançadas as competências básicas - fundamentos e pré-requisitos -, a criança já terá elementos para decodificar. E se decodificar significa usar o princípio alfabético, utilizando o conhecimento sobre as relações entre letras e sons linguísticos distintivos (transformar sons em letras = escrever e letras em sons $=$ ler), o primeiro passo é apresentar essas relações letras/sons à criança, levando-a a refletir conscientemente sobre elas. Oliveira (2007) propõe que primeiro se apresente o nome da letra e depois o som. No momento seguinte é que se ensina a juntar as letras para ler a palavra e, nesse processo, recomenda usar textos foneticamente adequados para que o iniciante consiga juntar as letras. Fundamentados em suas pesquisas, tanto Oliveira (2007) quanto Scliar-Cabral (2013) propõem formas de apresentar as relações grafema-fonema, cuja estrutura e sequência de ensino obedece a alguns critérios. Oliveira, no Programa Alfa e Beto, propõe que se comece pelas vogais e consoantes, apresentando os sons mais regulares, mais frequentes, sons fricativos antes dos sons oclusivos. Scliar-Cabral detalha os fundamentos para a escolha dos grafemas, postulando que uma ou duas letras (os grafemas) devem ser ensinados por seus valores e não por seu nome. A autora apresenta ainda algumas estratégias que podem ser utilizadas no processo de ensino-aprendizagem, as quais são descritas nas unidades do Sistema Scliar de Alfabetização - Roteiros para o professor: $1^{\circ}$ Ano. Citam-se esses dois pesquisadores pela relevância nacional e internacional de suas publicações no que se refere à alfabetização no Brasil. 


\section{CONSIDERAÇÕES FINAIS}

Ao longo deste texto foram enfatizados certos aspectos cognitivos facilitadores do aprendizado da leitura, cujo conhecimento por parte do professor pode promover e consolidar o aprendizado (da leitura) pela criança, mesmo antes do período de alfabetização, propriamente, dito. É óbvio que não existe uma maneira única de ensinar, como também não é aceitável ensinar de qualquer maneira. Em pesquisa anterior, (LANDIM, 2017) constatou que, ao término do ciclo de alfabetização, algumas crianças não dominavam aspectos básicos da leitura, sendo que muitas delas não conseguiram superar as dificuldades impostas pela relação grafema-fonema, o que comprometia a decodificação e, por conseguinte a leitura.

Esses dados sinalizam que intervenções precisam ser feitas antes, no início e durante o processo de alfabetização, para que resultados negativos como os apontados pela pesquisadora e pelas avaliações externas não continuem se repetindo. Em decorrência, faz-se necessário compreender o processo de aprendizagem da leitura e as intervenções que podem ser feitas pelos professores e também pelos pais, que podem contribuir para que as crianças tenham sucesso nas tarefas relacionadas à leitura. Destaca-se, além disso, a importância da relação da criança no seio familiar ser rica em experiências que contemplem a leitura, o manuseio de livros, a contação de histórias, dentre outras atividades que a família pode desenvolver com ela e que podem promover o desenvolvimento das competências fundamentais para o aprendizado da leitura.

Em seguida, na educação infantil, enfatiza-se a importância das atividades orais que possibilitam à criança brincar com a língua, como as cantigas, as parlendas, os travalínguas, as brincadeiras de escuta, de identificação de sons, os jogos de faz de conta, as representações teatrais e atividades mais elaboradas, que permitam a identificação de rimas, a criação de novas rimas, de mudar partes da palavra, de encontrar palavras escondidas, entre outras, são cruciais. Se este trabalho de percepção da língua oral e também visual (olhar para o que está escrito), bem como o contato com a leitura e práticas de contação de histórias e manuseio de livros tiver acontecido antes de a criança ingressar no primeiro ano e se o trabalho pedagógico for eficiente, ela levará alguns meses apenas para se alfabetizar. Certamente, não precisará de três anos para completar o ciclo de alfabetização.

Porém, se ao ingressar no primeiro ano, a criança não dominar as competências básicas, isso não pressupõe insucesso. Basta que o professor organize um roteiro de atividades e paute o planejamento das primeiras semanas de aula nos fundamentos e prérequisitos da leitura. É importante que o alfabetizador esteja consciente de que de sua atitude dependerá o sucesso ulterior em leitura de seu aluno. Também é imprescindível que o professor alfabetizador seja um estudioso, que conheça os processos cognitivos envolvidos na leitura para que assim possa, efetivamente, facilitar o aprendizado da leitura pela criança.

Falar em consciência fonológica como preditor de leitura, mas não ensinar a criança a refletir sobre a língua é o mesmo que querer que ela leia expressivamente e compreenda sem ter-lhe ensinado os caminhos que levam ao reconhecimento das palavras e à 
automatização do decifrado para poder buscar a compreensão. É esperar 'milagres' sem ter contribuído, sem ter feito a sua parte, prejudicando muito o jovem leitor cheio de curiosidade sobre a escrita e seu significado.

\section{REFERÊNCIAS}

ARAÚJO, A. P. Aprendizagem infantil: uma abordagem da neurociência, economia e psicologia cognitiva / Aloísio Pessoa de Araújo, coordenador. - Rio de Janeiro: Academia Brasileira de Ciências, 2011.

BRYANT,P.; GOSWAMI, U. Beyond grápeme-phoneme correspondence. Cahiers de Psychologie Cognitive - European Bulletin of CognitivePsychology, v.7, p.439-443.

CAPOVIlLA, A. G. S., \& CAPOVILLA, F. C. (2003). Alfabetização: Método fônico. São Paulo: Memmon.

CARDOSO-MARTINS, C. (1995). Consciência fonológica e alfabetização. Petrópolis: Vozes.

CARDOSO, C. V.; MOTA, M. M. P. E. Home-Literacy e os precursores da alfabetização. In: Estudos e pesquisa em Psicologia - Instituto de Psicologia da UERJ Universidade do Estado do Rio de Janeiro. v.15, n.2 (2015). Disponível em: http://www.e-publicacoes.uerj.br/index.php/revispsi/issue/view/1050

DEHAENE, S. Os neurônios da leitura: como a ciência explica a nossa capacidade de ler. Tradução: Leonor Scliar-Cabral. Porto Alegre: Penso, 2012.

HULME, C. Reading retardation and multi-sensory teaching. London: Routledge \& Keegan Paul, 1981.

HULME, C.; BRADLEY, L.. An experimental study of multisensory teaching with normal and retarded readers. In R. Malatesha \& H. Whitaker (Eds.), Dyslexia: A global issue. The Hague: Martinus Nijhoff, 1984.

HULME, C; MONK, A.; IVES, S. Some experiential studies of multi-sensory teaching: The effects of manual tracing on children's paired associated learning. British Journal of Developmental Psychology, 5, 299-307, 1987.

ISCOA, J.A. El alprendizaje de la lectura y sus dificultades: um enfoque psicolinguístico. In: TREVISAN, A.; MOSQUERA, J.J.M.; PEREIRA, V.M. (Orgs.). Alfabetização e cognição. Porto Alegre: EDIPUC, 2011.

GUIMARÃES, S. R. K. (2005). Aprendizagem da leitura e da escrita: O papel das habilidades metalinguísticas. São Paulo: Vetor.

LANDIM, M. R. M. Compreensão leitora: possibilidades de avaliação ao término do ciclo de alfabetização. Dissertação (Mestrado em Letras) - Universidade de Santa Cruz do Sul, 2017. 
MALUF, M. R. (2010). Do conhecimento implícito à consciência metalinguística indispensável na alfabetização. In S. R. K. Guimarães, \& M. R. Maluf (Eds.). Aprendizagem da linguagem escrita: Contribuições de pesquisa, coleção psicologia da linguagem (pp. 17-32). São Paulo: Vetor.

MORAIS, J. Criar leitores: para professores e educadores. Barueri-São Paulo: Minha Editora, 2013.

Alfabetizar para Democracia. Porto Alegre: Penso, 2014.

NAVAS, A. L. G. P. et al. Avanços no conhecimento do processamento da fluência em leitura: da palavra ao texto. In: Revista Sociedade Brasileira de Fonoaudiologia, 2009, p.553-559.

OLIVEIRA, J.B.A. ABC do alfabetizador. 5. ed. Belo Horizonte: Alfa Educativa, 2007.

REIS, A.; FAÍSCA, L.; CASTRO, S. L.; PETERSSON, K. M. Preditores da leitura ao longo da escolaridade: alterações dinâmicas no papel da consciência fonológica e da nomeação rápida, Trabalho apresentado em VII Simpósio Nacional de Investigação em Psicologia, In: Livro de Resumos do VII Simpósio Nacional de Investigação em Psicologia, Braga, 2010.

SCLIAR-CABRAL, L. Pela melhoria da qualidade na alfabetização. Rev. Estudos Legislativos, Porto Alegre, ano 9, n. 9, p. 21-38, 2015.

Ed. Lili, 2013.

Sistema Scliar de alfabetização: Fundamentos. Florianópolis:

SEYMOUR, P. H. K.; ARO, M.; ERSKINE, J. M. Foundation literacy acquisition in European orthographies. British Journal of Psychology, 94, 143-174, 2003.

SÉNÉCHAL, M., LeFEVRE, J., Thomas, E., \& DALEY, K (1998). Differential effects of home-literacy experiences on the development of oral and written language. Reading Research Quarterly, 33, 96-116.

SIQUEIRA, M.; ZIMMER, M. C. Aspectos linguísticos e cognitivos da leitura. In: Revista de Letras, n 28, jan./dez. 2006.

SNOWLING, M.; HULME, C. A ciência da leitura. Porto Alegre: Penso, 2013.

SOARES, Magda. Alfabetização: a questão dos métodos. São Paulo: contexto, 2017.

STANOVICH, K. E. Matthew effects in reading: Some consequences of individual differences in the acquisition of literacy. In: Reading Research Quaterly. Outono de 1986.

Recebido em: 15/06/2018 Aprovado em: 08/10/2018 Publicado em: 31/12/2018 